\title{
CYP27A1 expression in gilthead sea bream (Sparus auratus, L.): effects of calcitriol and parathyroid hormone-related protein
}

\author{
Gideon S Bevelander, Elsa S L C Pinto ${ }^{1}$, Adelino V M Canario ${ }^{1}$, Tom Spanings and Gert Flik \\ Department of Animal Physiology, Faculty of Science, Radboud University Nijmegen, Toernooiveld 1, 6525 ED Nijmegen, The Netherlands \\ ${ }^{1}$ Centre of Marine Sciences (CCMAR), University of Algarve, Campus de Gambelas, 8005-139 Faro, Portugal \\ (Correspondence should be addressed to G Flik; Email: g.flik@science.ru.nl)
}

\begin{abstract}
Little is known about vitamin D metabolism in fishes. Several reports have shown hydroxylase activities in various organs to produce vitamin D metabolites, but the enzymes involved have not been isolated or characterized. We isolated and characterized a renal mitochondrial hydroxylase, CYP27A1, that governs vitamin D metabolism in gilthead sea bream, Sparus auratus. The enzyme is highly expressed in kidney and to a far lesser extent in liver. When treated with 25-hydroxy vitamin $\mathrm{D}$ or calcitriol, the kidney responded differentially
\end{abstract}

and time dependently with CYP27A1 mRNA expression levels. This response substantiates a role for CYP27A1 in fish vitamin $\mathrm{D}$ metabolism. This notion is strengthened by upregulation of CYP27A1 in sea bream treated with parathyroid hormone-related protein $(\mathrm{PTHrP})$, and suggests an original role for $\mathrm{PTHrP}$ in calcitriol-regulated processes $\mathrm{n}$ fish similar to the role of $\mathrm{PTH}$ in mammalian vitamin D-dependent processes.

Journal of Endocrinology (2008) 196, 625-635

\section{Introduction}

Vitamin $\mathrm{D}_{3}$ requires transformations to become bioactive. These transformations involve cytochrome P450 (CYP) enzymes that hydroxylate the steroid. In mammals, the most abundant source of CYP enzymes is the liver, where a first hydroxylation takes place: the 25-carbon is hydroxylated to produce the intermediate 25-hydroxycholecalciferol (Jones et al. 1998). The proper enzyme activity responsible for this 25-hydroxylation is still rather enigmatic, even in mammals; several candidate enzymes with 25-hydroxylase ability and broad substrate specificity have been proposed (Aiba et al. 2006). One example is the sterol 27-hydroxylase (CYP27A1), which carries out the 25-hydroxylation of vitamin $\mathrm{D}_{3}$ as well as the 27-hydroxylation of cholesterol in bile acid biosynthesis (Ibarra et al. 2004). In mammalian kidney, 25-hydroxycholecalciferol is once more hydroxylated into more potent metabolites, viz. $1 \alpha, 25$-hydroxyvitamin $\mathrm{D}_{3}$ (calcitriol) and 24R,25-dihydroxycholecalciferol; CYP27B1 makes calcitriol and CYP24 produces 24R,25-dihydroxycholecalciferol. It is noteworthy that, CYP24 also uses calcitriol to produce $1 \alpha, 24 \mathrm{R}, 25-$ trihydroxycholecalciferol, the first product in the C-24 oxidation pathway responsible for degradation of calcitriol.

Comparatively little is known in teleosts concerning 'vitamin $\mathrm{D}_{3}$ physiology'. Indeed, classical genome-mediated responses to calcitriol have been demonstrated: calcitriol treatments in vivo elevate plasma calcium and/or phosphate levels (Larsson et al. 2003). Also, differential responses in non-genomic effects of vitamin $\mathrm{D}_{3}$ metabolites have been reported, in euryhaline trout kept in either fresh water or seawater (Larsson et al. 2003) or between stenohaline species (freshwater carp and seawater cod; Larsson et al. 2001). Calcitriol increases active calcium transport in gut of freshwater (FW) fish, but not so in saltwater (SW) fish. The metabolite 24R,25-dihydroxycholecalciferol was reported to decrease intestinal calcium transport in freshwater fish (Larsson et al. 2001, 2003).

In mammalian calcium homeostasis, parathyroid hormone (PTH) and calcitriol act synergistically through a strict regulation of CYP27B1 and CYP24 activities. Calcitriol controls its own degradation by induction of CYP24 expression and suppression of CYP27B1 expression; PTH induces CYP27B1 expression and downregulates CYP24 (Jones et al. 1998).

The array of endocrines involved in the calcemic control in fish includes PTH-related protein (PTHrP), a key in calcium balance in fish (Abbink \& Flik 2007, Guerreiro et al. 2007); more recently, $P T H$ genes have been demonstrated in zebrafish (Danks et al. 2003) and pufferfish (Gensure et al. 2004), but our understanding of the role of the peptides coded by these genes in the calcium physiology of fishes awaits further study (Abbink \& Flik 2007). A relationship between PTHrP and calcitriol in calcemic control was recently established for sea bream (Abbink et al. 2007); it was shown that a decrease of plasma calcitriol levels, due to dietary vitamin $\mathrm{D}_{3}$ deficiency, result in an adjustment of (hypercalcemic) PTHrP activities in gills and pituitary cells. Apparently, PTHrP and calcitriol fulfill concerted 
hypercalcemic functions in fish, reminiscent of those of PTH and calcitriol in higher vertebrates.

Remarkably, little is known about the way vitamin $\mathrm{D}_{3}$ metabolism takes place in fish. A 25-OHD-1-hydroxylase activity has been detected in several fish species (Henry \& Norman 1975) and the production of vitamin $\mathrm{D}_{3}$ metabolites has been demonstrated in vivo and in vitro in kidney and liver of trout, carp, halibut species, Atlantic salmon, Atlantic mackerel, and Atlantic cod (Hayes et al. 1986, Takeuchi et al. 1991, Graff et al.

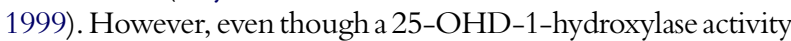
has been detected, the enzyme itself has never been isolated.

We report here the isolation and characterization of a gilthead sea bream CYP27A1 cDNA, the tissue distribution of gene expression and the effects of vitamin $\mathrm{D}_{3}$ metabolites and $\mathrm{PTHrP}$ on its expression.

\section{Materials and Methods}

\section{Fish}

Juvenile, male gilthead sea bream (Sparus auratus L.) of $\sim 160$ $180 \mathrm{~g}$ were obtained from a commercial source (TiMar, Culturas em Água, Lda., Portugal). The fish were kept in 10001 stock tanks with running seawater (flow, $250 \mathrm{l} / \mathrm{h}$ ); the salinity was $36 \%$ and the water temperature was $22{ }^{\circ} \mathrm{C}$. The fish were kept under natural photoperiod (14 h light:10 h darkness); the fish stock was fed daily commercial pellets (PROVIMI, Alverca, Portugal) at a ratio of $1 \%$ of the total estimated body mass per tank. Experiments were carried out in Portugal and approved by the local ethical committee.

\section{Cloning and characterization of CYP27A $c D N A$ from} S. auratus

A $300 \mathrm{bp}$ cDNA fragment was obtained when attempting to isolate a cDNA for 25-hydroxyvitamin $\mathrm{D}_{3} 1 \alpha$-hydroxylase (CYP27B1) from sea bream kidney using degenerate primers (1 $\alpha . f w 3: 5^{\prime}$-CT (AGC) CT (AG) G (GC) (GCT) GG (AC) GT (GCT) GAC-3'; 1 $\alpha$. rev3: $5^{\prime}$-(ACT) GA (ACT) GT (GT) G (AC) (AG) TAGTG (AG) CA-3') giving the highest BLASTX score to vitamin $\mathrm{D}_{3}$-25-hydroxylase (CYP27A) when searching against the GenBank database (Altschul et al. 1990). The complete coding sequence of CYP27A was obtained by screening at high stringency (in Church-Gilbert buffer at $55^{\circ} \mathrm{C}$ ) with the radiolabeled cDNA probe (Rediprime II random labeling kit, Amersham Pharmacia Biosciences) a sea bream kidney cDNA library constructed in Lambda Zap using the UNIZAP vector (Stratagene, La Jolla, CA, USA). After screening $6 \times 10^{5}$ recombinants, six independent clones were autoexcised in pBluescript phagemid using helper phage and sequenced. Two clones were smaller and not further analyzed; the other four were identical to the sequence described here. The putative CYP27A cDNA was identified by searching the GenBank database with BLASTN and BLASTX. The sequence is deposited in EMBL with accession number AM885865.

\section{Tissue distribution of CYP27A}

Fish were deeply anesthetized with 2-phenoxyethanol $(0 \cdot 1 \% \mathrm{v} / \mathrm{v}$; Sigma-Aldrich) and the whole pituitary gland, gill, liver, kidney, head kidney, muscle, foregut, midgut, and rectum were sampled. For mRNA extraction, tissues were flash-frozen on dry ice and stored at $-80^{\circ} \mathrm{C}$ until further use.

\section{Phylogenetic analysis CYP27A1}

Available vertebrate CYP27A1 sequences were taken from the NCBI site (www.ncbi.nih.gov) via the GenBank database. Multiple sequence alignments were accomplished with the ClustalW program from the European Bioinformatics Institute (www.ebi.ac.uk/clustalw/). With the neighborjoining method, and Mega version 3.1 (Kumar et al. 2004), a phylogenetic tree was constructed on the basis of amino acid difference ( $P$ distance) with 1000 bootstrap replications.

\section{Physiology}

Fish $(n=8)$ randomly selected from their stock tank, one group per time point, were placed in cylindrical 5001 tanks (diameter of tank, $0 \cdot 85 \mathrm{~m}$ ). Fish were left to acclimatize for at least 1 week; feeding was discontinued $24 \mathrm{~h}$ before the start of the experiments.

Vitamin D metabolites 1 $\alpha, 25$-dihydroxyvitamin $\mathrm{D}_{3}$ (calcitriol) or 25-hydroxycholecalciferol (25-OHD) were dissolved in a minimal amount of absolute ethanol and diluted in coconut oil. Fish received a single i.p. injection of coconut oil containing calcitriol $(25 \mu \mathrm{g} / \mathrm{kg}$ bodyweight $(\mathrm{BW}))$ or 25 -hydroxycholecalciferol $(50 \mu \mathrm{g} / \mathrm{kg} \mathrm{BW})$ or vehicle only. Fish were sampled 3, 6, and 9 days after injection. In pilots, no effects of these treatments were seen in the first $48 \mathrm{~h}$ following injection; therefore 3, 6, and 9 days were considered, in line with similar slow responses to, for example, estrogens in this fish (Bevelander et al. 2006).

PTHrP Fish were injected intraperitoneally with saline $(0 \cdot 9 \% \mathrm{NaCl})$ or either Fugu PTHrP (1-34; Danks et al. 2003) or the recombinant full length sea bream PTHrP $(s b \mathrm{PTHrP}$ 1-125). For both the forms, the dose was $10 \mathrm{ng} / \mathrm{g} \mathrm{BW}$. Controls and treated groups were sampled 6 and $24 \mathrm{~h}$ after injection. The choice for these sampling times was based on pilots where maximum effects were seen within $48 \mathrm{~h}$.

\section{Sampling procedure}

Fish were deeply anesthetized with 2-phenoxyethanol $(0 \cdot 1 \%$ $\mathrm{v} / \mathrm{v}$; Sigma-Aldrich), and blood was taken by puncturing the caudal vessels with a $1 \mathrm{ml}$ tuberculin syringe, rinsed with ammonium heparin (Sigma (H-6279) dissolved in $0.9 \% \mathrm{NaCl}$ $(\mathrm{v} / \mathrm{v})$, at $300 \mathrm{units} / \mathrm{ml})$. The fish were then killed by spinal transection and blood was collected. The collected blood was centrifuged at $13600 \mathrm{~g}$ for $10 \mathrm{~min}$ and the plasma stored 
at $-20{ }^{\circ} \mathrm{C}$ until analysis (see below). Next, liver and kidney samples were quickly collected and flash-frozen in liquid nitrogen and stored at $-80^{\circ} \mathrm{C}$ for later analysis of mRNA expression (see below).

\section{Plasma analyses}

The 25-OHD concentration in the plasma was measured by a 25-OHD RIA method (IDS Ltd, Boldon, UK). Briefly, two extraction reagents were added to $50 \mu 1$ standards and samples resulting in the precipitation of serum proteins and extraction of 25-OHD. After centrifugation $(10 \mathrm{~min}$ at $2000 \mathrm{~g}), 50 \mu \mathrm{l}$ extract supernatant were taken from standards and samples. For each sample, supernatant was incubated with ${ }^{125}$ I-labeled $25-\mathrm{OHD}$ and a specific sheep antiserum $\left(90 \mathrm{~min}\right.$ at $\left.18-25^{\circ} \mathrm{C}\right)$. The bound fraction was separated from the free fraction by a short incubation with Sac-Cel $\left(20 \mathrm{~min}\right.$ at $\left.18-25^{\circ} \mathrm{C}\right)$ and followed by centrifugation $(10 \mathrm{~min}$ at $2000 \mathrm{~g}$ ). The supernatant was discarded and the precipitate reflecting the bound fraction was counted in a $\gamma$-counter. The bound radioactivity is inversely proportional to the concentration of $25-\mathrm{OHD}$. The intra- and inter-assay coefficients of variation were 5 and $8 \%$ respectively. Stripped plasma spiked with defined levels of 25-OHD gave highly predictable results (data not shown).

\section{CYP27A $m R N A$ expression}

Relative expression of CYP27A mRNA was assessed using quantitative RT-PCR. Tissue was homogenized in TRIzol reagent (Invitrogen) and total RNA was extracted according to the manufacturer's instructions. RNA $(1 \mu \mathrm{g})$ was incubated with $1 \mathrm{U}$ DNase I (amplification grade; Invitrogen) for $15 \mathrm{~min}$ at room temperature to remove genomic DNA. To inactivate DNase activity and linearize RNA, $1 \mu \mathrm{l}$ of $25 \mathrm{mM}$ EDTA was added and the sample incubated for $10 \mathrm{~min}$ at $65^{\circ} \mathrm{C}$. Next, $1 \mu \mathrm{g}$ RNA was reverse transcribed (RT) with $300 \mathrm{ng}$ random primers, $0.5 \mathrm{mM}$ dNTPs, 10 units RNase inhibitor (Invitrogen), $10 \mathrm{mM}$ dithiothreitol, and $200 \mathrm{U}$ Superscript II RT (Invitrogen) for $50 \mathrm{~min}$ at $37^{\circ} \mathrm{C}$.

For quantitative PCR analysis, five times diluted $5 \mu \mathrm{RT}$ mix was used as a template in $25 \mu \mathrm{l}$ amplification mixture, containing 12.5 $\mu \mathrm{l}$ SYBR Green Master Mix (Applied Biosystems Benelux, Nieuwerkerk aan den IJsel, The Netherlands), $3 \mu \mathrm{l}$ each primer (final concentration
$600 \mathrm{nM})$. The primer sets used in the RT-PCR for elongation factor- $1 \alpha$ (EF-1 $\alpha$ ) were: qFWEF- $1 \alpha$ and qRVEF- $1 \alpha$, for $\beta$-actin: qFWACTIN and qRVACTIN, and for CYP27A: qFWCYP27 and qRVCYP27 (Table 1).

All primer sets had an efficiency over $98 \%$ and all products showed a single melting transition. After an initial step at $95^{\circ} \mathrm{C}$ for $10 \mathrm{~min}$, a real-time quantitative PCR of 40 cycles was performed (GeneAmp 7500, Applied Biosystems) with each cycle consisted of $15 \mathrm{~s}$ denaturation at $95^{\circ} \mathrm{C}$ and 1 -min annealing and extension at $60^{\circ} \mathrm{C}$. The cycle threshold values were determined and the expression was calculated as a percentage of EF- $1 \alpha$ or $\beta$-actin (Pfaffl et al. 2002). All samples were assayed in duplicate. Both house-keeping genes gave similar results. For clarity, results are presented here only relative to $\mathrm{EF}-1 \alpha$. Non-reverse transcriptase controls were consistently negative.

\section{Chemicals}

Calcitriol and 25-OHD were purchased from Sigma (SigmaAldrich). Pufferfish (Takifugu rubripes) PTHrP (1-34) was synthesized by Genemed Synthesis Inc. (San Francisco, CA, USA). Homologous recombinant parathyroid hormonerelated protein $s b \mathrm{PTHrP}(1-125)$ was produced in bacteria (Anjos et al. 2005).

\section{Statistical analysis}

Data are presented as mean \pm s.D. ANOVA was used to assess differences among groups, followed by the Bonferroni test to determine the level of significance (SPSS Windows version 14.0, Chicago, IL, USA). Significance was accepted when $P<0 \cdot 05$.

\section{Results}

\section{Cloning and characterization of CYP27A $c D N A$ from} S. auratus

The full length $2793 \mathrm{bp}$ cDNA CYP27A1 sequence containing an open reading frame encoding a protein of 471 amino acids is shown in Fig. 1. The amino acid identity of the sea bream sequence compared with Xenopus laevis, human, rat, and mouse is $45,40,41$, and $39 \%$ respectively.

Table 1 Primer sequences for real-time quantitative PCR

\begin{tabular}{|c|c|c|c|}
\hline & Primer & Sequence & Accession number \\
\hline \multicolumn{4}{|l|}{ Gene } \\
\hline $\mathrm{EF}-1 \alpha$ & $\begin{array}{l}\text { qFWEF- } 1 \alpha \\
\text { qRVEF- } 1 \alpha\end{array}$ & $\begin{array}{l}\text { gtg gag atg cac cac gag tct } \\
\text { cgt atc cac gac gga ttt cc }\end{array}$ & AF184170 \\
\hline$\beta$-actin & $\begin{array}{l}\text { qFWACTIN } \\
\text { qRVACTIN }\end{array}$ & $\begin{array}{l}\text { aag atg acc cag atc atg ttc ga } \\
\text { cga tac cag tgg tac gac cag a }\end{array}$ & AF384096 \\
\hline CYP27A & $\begin{array}{l}\text { qFWCYP27 } \\
\text { qRVCYP27 }\end{array}$ & $\begin{array}{l}\text { tg gct cta caa gtt tgg ctt tga } \\
\text { tga acc gca gcg tgt ctt t }\end{array}$ & AM885865 \\
\hline
\end{tabular}


1 ggcacgagatccaccgtcacaccgctcgcaccatgggctccccggttgcctcagctcggg

61 ctccceggctcgctgcgctctgtctccggacactcccggagctccgacacggcggaagga

4

121 ggctgaacgtccaggcggcgacagctgcggggaagctgaagagcatcglatgacctgccgg

$\begin{array}{lllllllllllllllllllll}24 & D & R & V & C & P & P & P & C & T & G & C & S & S & K & D & T & R & T & R & A\end{array}$

181 gaccgagtctgtccaccaccctgtactggctgttcgtcaaaggatacgcggacaagagcc

$\begin{array}{lllllllllllllllllllll}44 & M & L & Q & G & L & Q & R & N & L & Y & G & P & I & W & R & S & R & F & G & P\end{array}$

241 atgctgcagggtttacagaggaatctttatgggcccatctggcgctccaggttcggcccg

$\begin{array}{lllllllllllllllllllll}64 & \mathrm{Y} & \mathrm{D} & \mathrm{I} & \mathrm{V} & \mathrm{N} & \mathrm{V} & \mathrm{A} & \mathrm{T} & \mathrm{P} & \mathrm{E} & \mathrm{L} & \mathrm{I} & \mathrm{A} & \mathrm{Q} & \mathrm{V} & \mathrm{I} & \mathrm{H} & \mathrm{Q} & \mathrm{E} & \mathrm{G}\end{array}$

301 tacgacatcgttaatgtggcgactccagagctgatcgctcaggtgatccatcaggagggg

$\begin{array}{lllllllllllllllllllllll}84 & R & Y & P & V & R & A & E & L & P & H & W & K & E & Y & L & D & L & R & G & R\end{array}$

361 cgctacccggtccgagctgagctgcctcactggaaagagtacctggacctgagaggacgg

$\begin{array}{lllllllllllllllllllll}104 & A & Y & G & L & H & V & H & T & G & P & A & W & Y & N & I & R & S & A & L & N\end{array}$

421 gcctacggtctgcatgtgcacacaggaccggcgtggtacaacatccgcagcgccctgaac

$\begin{array}{llllllllllllllllllllll}124 & P & K & M & L & K & L & R & E & V & T & S & Y & A & P & I & I & H & Q & V & V\end{array}$

481 cccaagatgctgaagttgcgggaagtgacttcctacgccccgatcatccaccaggtggtc

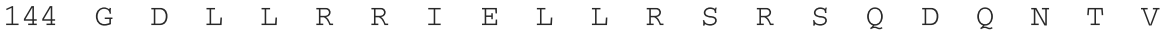

541 ggagatctgctgcgacgcatcgagctcctccgaagccgcagtcaggaccagaacaccgtt

$\begin{array}{lllllllllllllllllllll}164 & S & D & M & A & A & E & L & Y & K & F & G & F & E & G & I & S & S & I & L & F\end{array}$

601 tcagatatggctgctgagctctacaagtttggcttgaaggtatatcctccatcttgttt

$\begin{array}{llllllllllllllllllllllllllll}184 & \mathrm{E} & \mathrm{T} & \mathrm{R} & \mathrm{L} & \mathrm{G} & \mathrm{C} & \mathrm{L} & \mathrm{Q} & \mathrm{E} & \mathrm{E} & \mathrm{I} & \mathrm{P} & \mathrm{K} & \mathrm{D} & \mathrm{T} & \mathrm{L} & \mathrm{R} & \mathrm{F} & \mathrm{I} & \mathrm{T}\end{array}$

661 gagaccaggttgggctgcctgcaagaggagattcccaaagacacgctgcggttcatcact

$\begin{array}{lllllllllllllllllllll}204 & A & V & N & N & M & L & T & L & S & E & T & V & V & L & F & P & R & W & S & R\end{array}$

721 gccgtcaacaacatgctgacgctgtccgagactgtggtcctcttccetcgctggagccgt

$\begin{array}{lllllllllllllllllllll}224 & G & V & L & P & L & W & N & R & F & V & Q & A & W & D & D & L & Y & D & V & A\end{array}$

781 ggcgtcctccccttgtggaatcgcttcgttcaggcctgggacgacctctacgatgtggcc

$\begin{array}{lllllllllllllllllllll}244 & R & T & L & I & D & R & R & V & A & E & I & E & A & Q & V & C & S & G & E & P\end{array}$

841 aggaccctcatcgacaggagagtggctgaaattgaagctcaggtgtgcagtggcgagccg

$\begin{array}{llllllllllllllllllllllllllllll}264 & A & E & G & M & Y & L & T & Y & L & L & S & S & D & K & L & S & R & A & E & V\end{array}$

901 gcagagggcatgtacctgacctacctgctgtcctctgacaagctgtccagagccgaggtc

$\begin{array}{lllllllllllllllllllll}284 & Y & I & S & L & T & E & L & L & L & G & G & V & D & T & T & S & N & T & L & S\end{array}$

961 tacatcagcctcactgaactgctgctgggaggagtcgacacgacctccaacaccttgtcg

$\begin{array}{lllllllllllllllllllll}304 & W & A & L & Y & H & L & A & K & D & R & S & A & Q & D & R & L & Y & S & E & V\end{array}$

1021 tgggcgctgtaccatttagcgaaggaccgctcggctcaggatcgactgtacagcgaggtg

$\begin{array}{lllllllllllllllllllll}324 & N & S & V & C & P & D & R & R & E & P & T & T & D & N & L & T & M & M & P & Y\end{array}$

1081 aactctgtgtgtccggacagacgggagccgaccacagacaacctgaccatgatgccctac

$\begin{array}{lllllllllllllllllllll}344 & \mathrm{~L} & \mathrm{~K} & \mathrm{~A} & \mathrm{~V} & \mathrm{I} & \mathrm{K} & \mathrm{E} & \mathrm{T} & \mathrm{L} & \mathrm{R} & \mathrm{L} & \mathrm{Y} & \mathrm{P} & \mathrm{V} & \mathrm{V} & \mathrm{P} & \mathrm{G} & \mathrm{N} & \mathrm{G} & \mathrm{R}\end{array}$

1141 ctgaaagccgtcatcaaggagacgctacgtctttatccggtggtgcctggaaatggacga

$\begin{array}{lllllllllllllllllllll}364 & F & I & S & E & N & E & V & V & V & E & N & Y & W & F & P & K & K & T & Q & F\end{array}$

1201 ttcattcggagaatgaggtggttgtggaaaactactggttcccaaagaagactcagttc

$\begin{array}{lllllllllllllllllllll}384 & \mathrm{H} & \mathrm{L} & \mathrm{C} & \mathrm{H} & \mathrm{Y} & \mathrm{A} & \mathrm{A} & \mathrm{C} & \mathrm{H} & \mathrm{D} & \mathrm{E} & \mathrm{M} & \mathrm{E} & \mathrm{F} & \mathrm{V} & \mathrm{D} & \mathrm{P} & \mathrm{E} & \mathrm{R} & \mathrm{F}\end{array}$

1261 cacctgtgtcactacgcagcctgtcacgatgagatggagtttgtcgacccggagcgcttc

$\begin{array}{llllllllllllllllllllll}404 & I & P & D & R & W & L & R & D & V & A & P & S & S & G & H & Y & R & H & H & P\end{array}$

1321 atcccggatcggtggctccgcgacgtggcgcccagcagcggccactaccgacaccacccg

$\begin{array}{lllllllllllllllllllll}424 & Y & S & F & I & P & F & G & V & G & V & R & A & C & V & G & K & R & V & A & E\end{array}$

1381 tacagcttcatcccattcggtgtcggcgtgcgggcctgtgtggggaagagggtggcggag

$\begin{array}{lllllllllllllllllllll}444 & M & E & M & Y & F & A & L & S & R & L & M & Q & H & Y & E & V & Q & L & E & D\end{array}$

1441 atggagatgtacttcgctctgtccaggttgatgcagcactatgaggtccagctggaagat

$\begin{array}{lllllllllllllllllllll}464 & E & A & L & V & V & E & P & K & T & R & T & L & L & I & P & A & K & P & I & N\end{array}$

1501 gaagctttggtcgtggagccaaaaactcgaaccctgctcatccctgcgaagccaatcaac

471 L $R$ F L $\mathrm{S}$ R A *

1561 ctgcgcttcctgtccagagcctgaggagggcgccgctgagggtcaacacaacacgtcatc

1621 gcttccactccaccaatcacagcccagtcgtgtgttgttttttaaacccttcacaaat

1681 attttatttgctaacgattaatttcagaccaaagtcaaatacttagttactgtacttgag

1741 tacatgtctcaggtatttgtactttactcgagtatttattcccctctgaccttctcctc

1801 ctcacgtttcaaaacaggctcatcactttagtttgatgtatttgaggggaatgatggat

1861 tattttatttgccgtcattgtacaggatcaatctatctatccgtgcaaagctaactgaa

1921 gctaacgtcatattaatataattcaaacttcagagggagactttcactgtgatactctac

1981 ttttactcaagttaatttgactcgactgattctcttagtctttaattggagtgtttat

Figure 1 (continued) 
2041 ctttgaacttaatgaagttaatgctcagactttgccttctgcacgatcacatgataacat 2101 gataacatatataatcactgcatgtattcagtacatcctcgttcagcaaagctttcccgc

2161 ctggtgaactttgtatttacgcagatttgattcatcggtcttgtttgcaaagaagccgat

2221 gagtcaaagttcgatgagtcaaatctggtttgacattaataagaaggtgtgtttcagta

2281 gacactcactgttcccctctggcttaataactgatgagtttgaggatttatttaatgtt

2341 aatttgaactttgttcccctaattgtttttttaattgttaacagaaacttaaggaag

2401 tgggaggaaaggaagtcatttaacagctttatctgtttcattttaaatcactgttatat

2461 tttaatacagccacagctataaacttttcttgcacaagatttattttttacaccaaacg

2521 ttgatttaacgacttaaacaactttaaagagtctaagggcaacgacagtgtgtgaagatc

2581 agtttgtagttatttagttgaactgttatcgctgtaacactcctgcacagttatctctga

2641 cgatgttcttacagaataaatgaccttatatgtcgtctttctaacaatgtgaatattgt

2701 tctcctaaatgcttgtctaaaatgtcattaaattgaaagctgctacacaaataatat

2761 tcatatatttaattaaaaaaaaaaaaaaaa

Figure 1 Nucleotide and deduced amino acid sequence of Sparus CYP27A1. The deduced amino acid sequence is presented above the nucleotide sequence. The start codon is boxed black and the stop codon is indicated by an asterisk (*). The EBL accession number is AM885865.

To compare the sequence of sea bream with that of other vertebrate species, a multiple alignment was made (Fig. 2). The three conserved residues $\left(\mathrm{Lys}^{336}{ }^{3 \mathrm{Lys}^{340}}\right.$, and $\mathrm{Arg}^{403}$ ) essential for ferredoxin binding are indicated. Furthermore, two other sites are indicated: a well-conserved cysteine ${ }^{429}$ residue, where heme is covalently bound to the enzyme and a conserved site which is the putative oxygen-binding site.

A phylogenetic tree was constructed using the neighborjoining method (Fig. 3). Human, mouse, and xenopus CYP27B1 served as an outgroup. Mammalian CYP27A1 sequences are separated from the sea bream CYP27A1 sequence by chicken and xenopus CYP27A1, conform phylogeny. The predicted sequence of zebrafish clusters with the sequence of sea bream, but we do not include these data as the sequence is only predicted. No other fish sequences are known to us at this moment.

\section{Tissue distribution}

CYP27A1 gene expression was detected in pituitary gland, gills, intestine, head kidney, and muscle (Fig. 4) with an apparent absence in liver and highest abundance in kidney. The preparations of cDNA were of constant quality judged by consistent and highly reproducible amplification of the house-keeping gene EF- $1 \alpha$ in all samples.

\section{Expression of CYP27A1}

In the injection experiments (vitamin $\mathrm{D}$ metabolites and PTHrP), only two tissues were studied: liver and kidney. Neither treatment induced CYP27A1 expression to detectable levels in liver (data not shown); however, renal mRNA levels of CYP27A1 were markedly affected by the hormone treatments. The vitamin D metabolite 25-OHD (Table 2) induced a significant downregulation of CYP27A1 expression 3 days following injection; calcitriol did not induce apparent effects at this time point (Fig. 5A). However, 6 days post-injection, both calcitriol and 25-OHD significantly increased CYP27A1 expression (Fig. 5B). No differences in expression were observed 9 days of post-injection.
CYP27A1 mRNA levels were significantly upregulated following injection of PTHrP (1-125) as readily as after $6 \mathrm{~h}$ (Fig. 6A). PTHrP (1-34) had a mild but not statistically significant effect. At 24-h post-injection, neither PTHrP (1-34) nor PTHrP (1-125) resulted in changes in CYP27A1 expression (Fig. 6B).

\section{Discussion}

This study describes the complete cDNA sequence of CYP27A1 from gilthead sea bream. Quantitative analysis of mRNA expression shows abundant expression of CYP27A1 in the kidney, while liver expression levels are very low, an essentially reversed situation compared with the mRNA expression profiles in mammals. Injection of two different vitamin D metabolites, viz. 25-OHD and calcitriol, had differential and time-dependent effects on the expression of renal CYP27A1, 25-OHD being inhibitory on the shorter term (at 3 days), calcitriol and 25-OHD being stimulatory on the longer term (at 6 days). PTHrP can upregulate CYP27A1 mRNA levels, which suggests a similar role for PTHrP in fish as that of PTH (and PTHrP) in mammalian vitamin D metabolism. Indeed, consensus exists that PTHrP and PTH share common receptors in fish and mammals alike and thus such a finding for PTHrP in fish is not surprising as the $\mathrm{PTHrP}$ receptor is expressed in sea bream kidney and many other tissues (Hang et al. 2005, Rotllant et al. 2006).

\section{Molecular considerations}

Mitochondrial cytochrome P450s are monooxygenases receiving their electrons from NADPH via a two-protein redox chain consisting of ferredoxin reductase and ferredoxin. It has been shown that all mitochondrial $\mathrm{P} 450 \mathrm{~s}$ possess a conserved binding domain involved in the interaction of $\mathrm{P} 450$ s with their redox partner ferredoxin. There are two lysine residues considered crucial for this binding, and in human P450c27 (=CYP27A1) a third residue, the positively charged arginine at position 403 , was found to participate in 

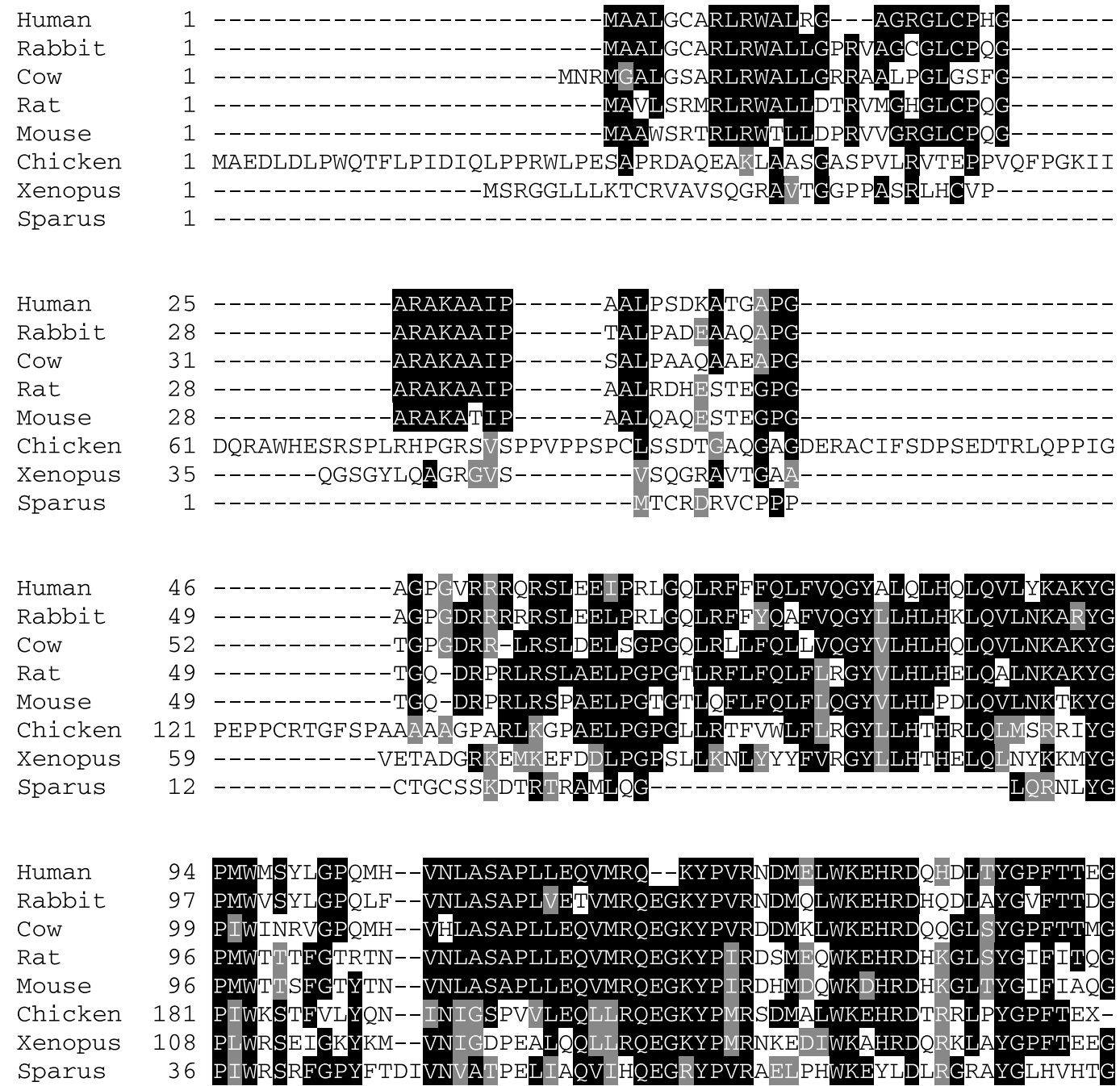

Human 150 HHWYQLRQALN--QR LKPAEAALYTDAFNEVIDDFMTRLDQLRAESASGNQVSDMAOLF Rabbit 155 HDWYQLRQALN--QRLLKPAEAALYTDALNEVIDSFVVRLDQLRAESASGDQVPDMADLI COW $\quad 157$ EQWYRLRQTLN--QRMLKPAEAALYTDALNEVINDFMDQLKQLRAESASGDHVPDIAHQF Rat 154 QQWYHLRHSLN--QRIVKPAEAALYTDALNEVISDFIARLDQVRTESASGDQVPDVANLL Mouse 154 EQWYHLRQALK--QR LKPDEAALYTDALNEVISDF ITRLDQVRAESESGDQVPDMAHLL Chicken 238 ---VRPRSDVG--MRIVEPSEAVLYADAIGAVVSDLMVRLRDERRCSPSGVLVGDVANLL Xenopus 166 YHWYRIRSVLN--KKMLKPSEASSYAGG INEVVTDFMNIKLQYMRKASPSGDMVNDVANAL Sparus 96 PAWYNIRSALNFTPKMLKLREVTSYAPI IHQVVGDLIRRIELLRSRSQDQNTVSDMAAEL

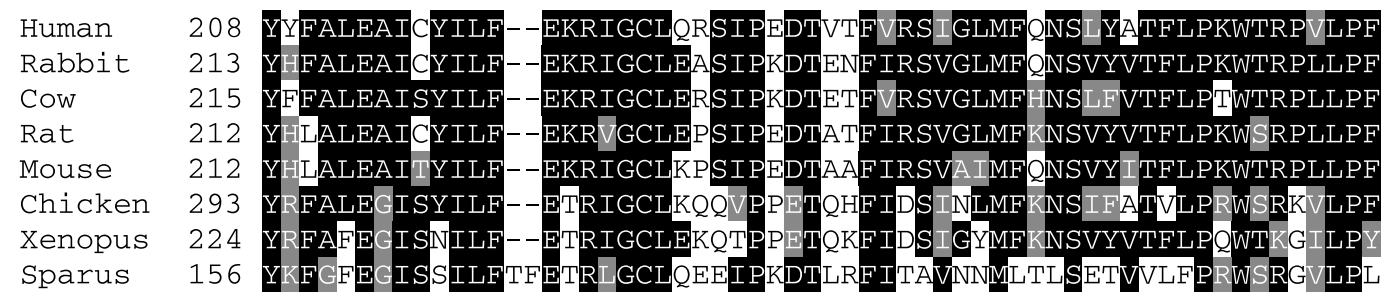

Figure 2 (continued) 

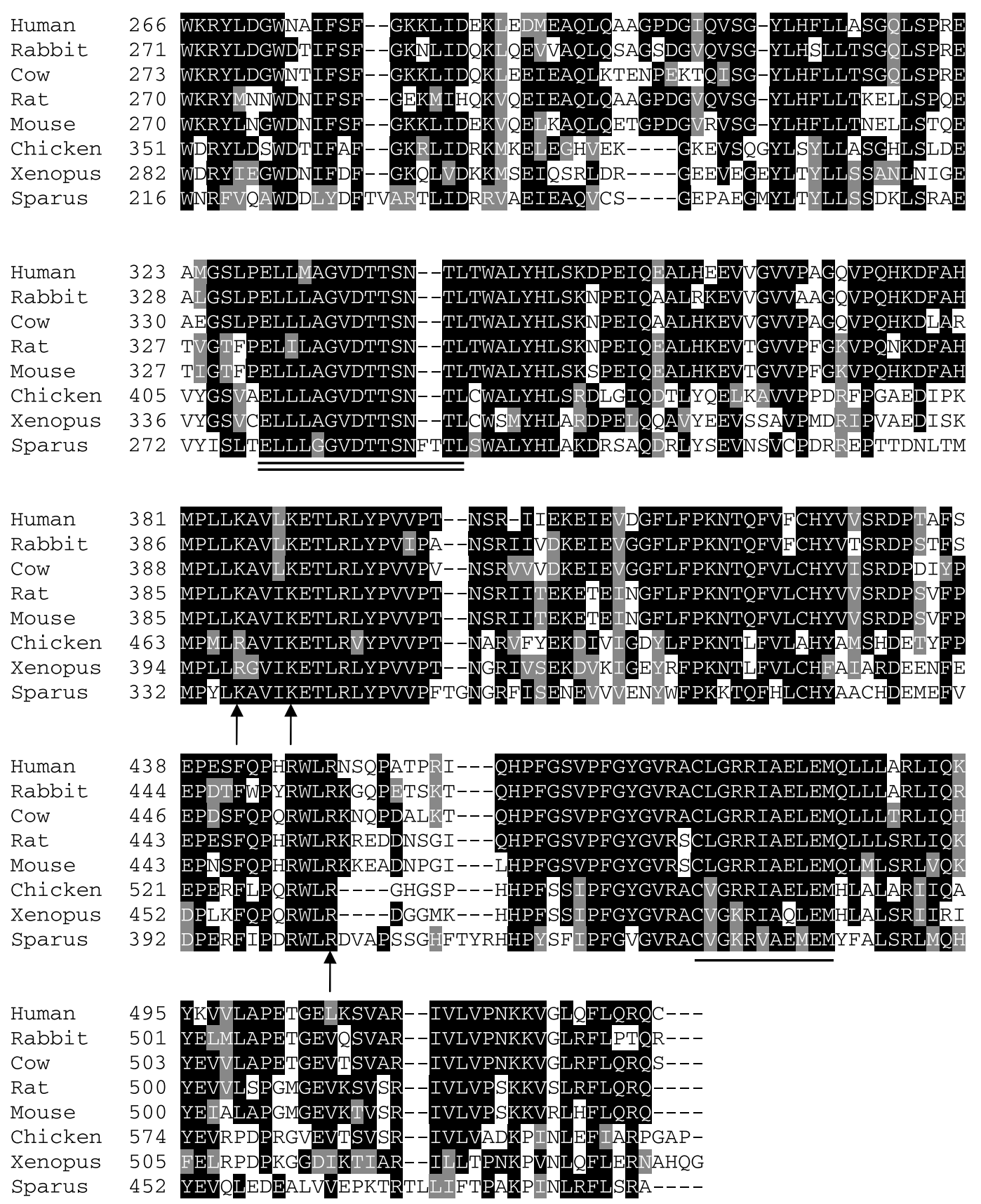

Figure 2 Alignment of CYP27A1s for eight vertebrate species. Hyphens indicate gaps that were introduced to achieve maximum identity. Identical amino acids are indicated in black boxes, conservative substitutions in gray. The two arrows close to each other indicate the two lysine residues and the third arrow indicates the arginine residue. A conserved cysteine residue, the ligand for the heme group, is indicated in an underlined block and a putative oxygen-binding site is indicated (doubly underlined). Accession numbers: human (Homo sapiens), NP_000775; rabbit (Oryctolagus cuniculus), P17177; cow (Bos taurus), XP_883724; mouse (Mus musculus), NP_077226; rat (Rattus norvegicus), NP_849178; chicken (Gallus gallus), XP_422056; and Xenopus (Xenopus laevis), AAH77308.

binding as well, making the bond tighter (Pikuleva et al. 1999). These three conserved residues are found in all vertebrate CYP27A1 sequences (Fig. 2) and indeed must be highly relevant for the functioning of the enzyme. The conserved cysteine ${ }^{429}$ responsible for heme binding and a conserved site for oxygen binding are found not only in all known CYP27A1s but also in other vitamin D-related cytochromes (Jones et al. 1998). This taken together with 

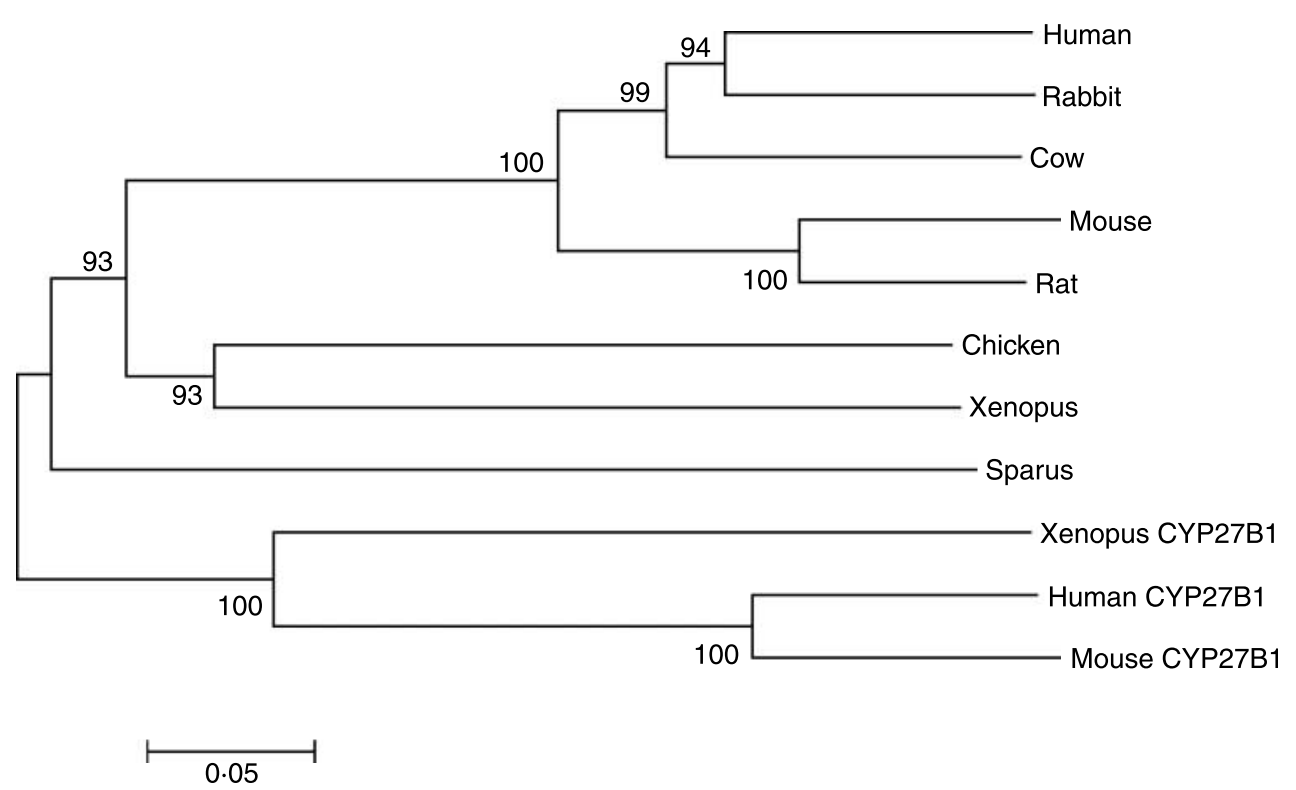

Figure 3 Phylogenetic tree of CYP27A1 sequences constructed using the neighbor-joining method. Numbers at the branch nodes represent the confidence levels of 1000 boot strap replications. Human, mouse, and Xenopus tropicalis (Xenopus CYP27B1) CYP27B1 served as an outgroup. Accession numbers as in Fig. 2. Additional accession numbers: human (Homo sapiens), NP_000776; mouse (Mus musculus), NP_034139; and Xenopus (Xenopus tropicalis), NP_001006907.

significant yet moderate overall amino acid homology (homology for consensus sequences within the protein such as the heme- and the oxygen-binding regions are very much higher indeed) and the clustering in phylogenetic analyses, confirms the identity of the sea bream enzyme presented here as a mitochondrial CYP27A1.

\section{5-Hydroxylation}

The mammalian liver and several extrahepatic tissues possess mitochondrial enzyme activities that hydroxylate the

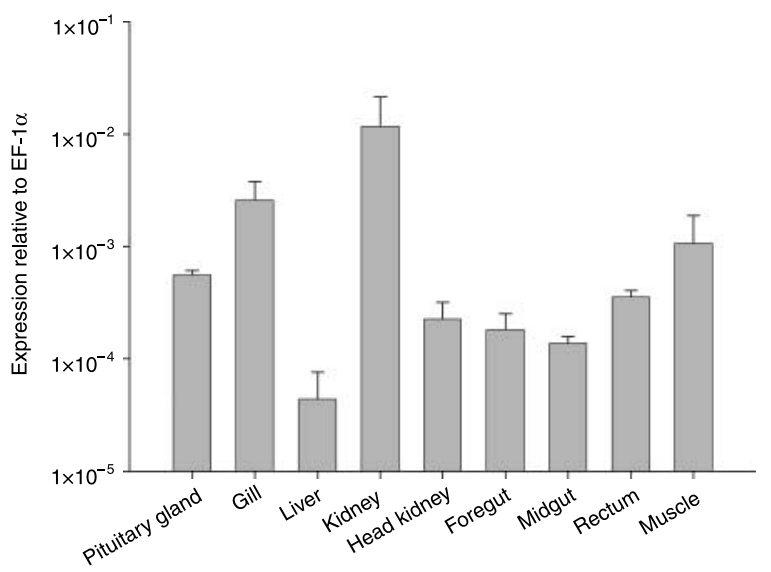

Figure 4 Expression of Sparus CYP27A1 as determined by quantitative RT-PCR. Data are presented as mean \pm s.D. $(N=5)$. 25-carbon of vitamin $\mathrm{D}_{3}$ and other steroids (Bhattacharyya \& DeLuca 1974, Bjorkhem et al. 1980). The presumed enzyme was first identified as a broad spectrum sterol 27-hydroxylase with a designated role in hepatic bile acid biosynthesis, catalyzing the first step in the oxidation of the cholesterol side chain in the 'acidic' bile biosynthesis pathway (Cali \& Russell 1991). Consensus has been reached now that an extrahepatic CYP27A1 serves this role in cholesterol homeostasis and efficient clearance of cholesterol (Babiker et al. 1997). Further support for extrahepatic 25-hydroxylase activity came from studies that show expression of CYP27A1 in the brain, vascular endothelium, kidney, and liver (Andersson et al. 1989, Reiss et al. 1997); a situation that, with the exception of what we describe here for the liver, is comparable with that in sea bream tissues.

Table 2 25-OHD plasma levels (nM) following 25-OHD and calcitriol treatment of seawater sea bream

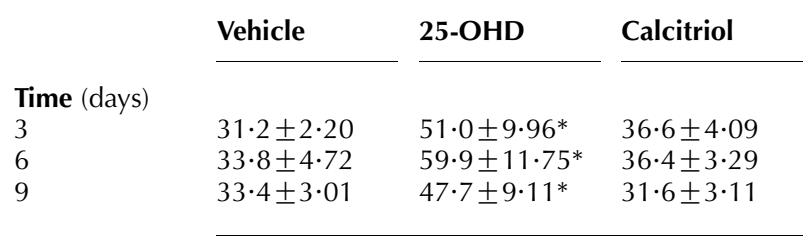

Seawater sea bream were injected with vehicle or hormones (see Materials and Methods) and sampled for blood 3, 6, and 9 days later. Plasma was analyzed for 25-OHD; vehicle-treated fish did not differ in time nor did calcitriol affect 25-OHD levels compared with vehicle-treated fish; 25-OHDinjected fish had elevated plasma levels of $25-\mathrm{OHD}\left({ }^{*} P<0 \cdot 05 ; n=9\right)$ for the duration of the experiment. 

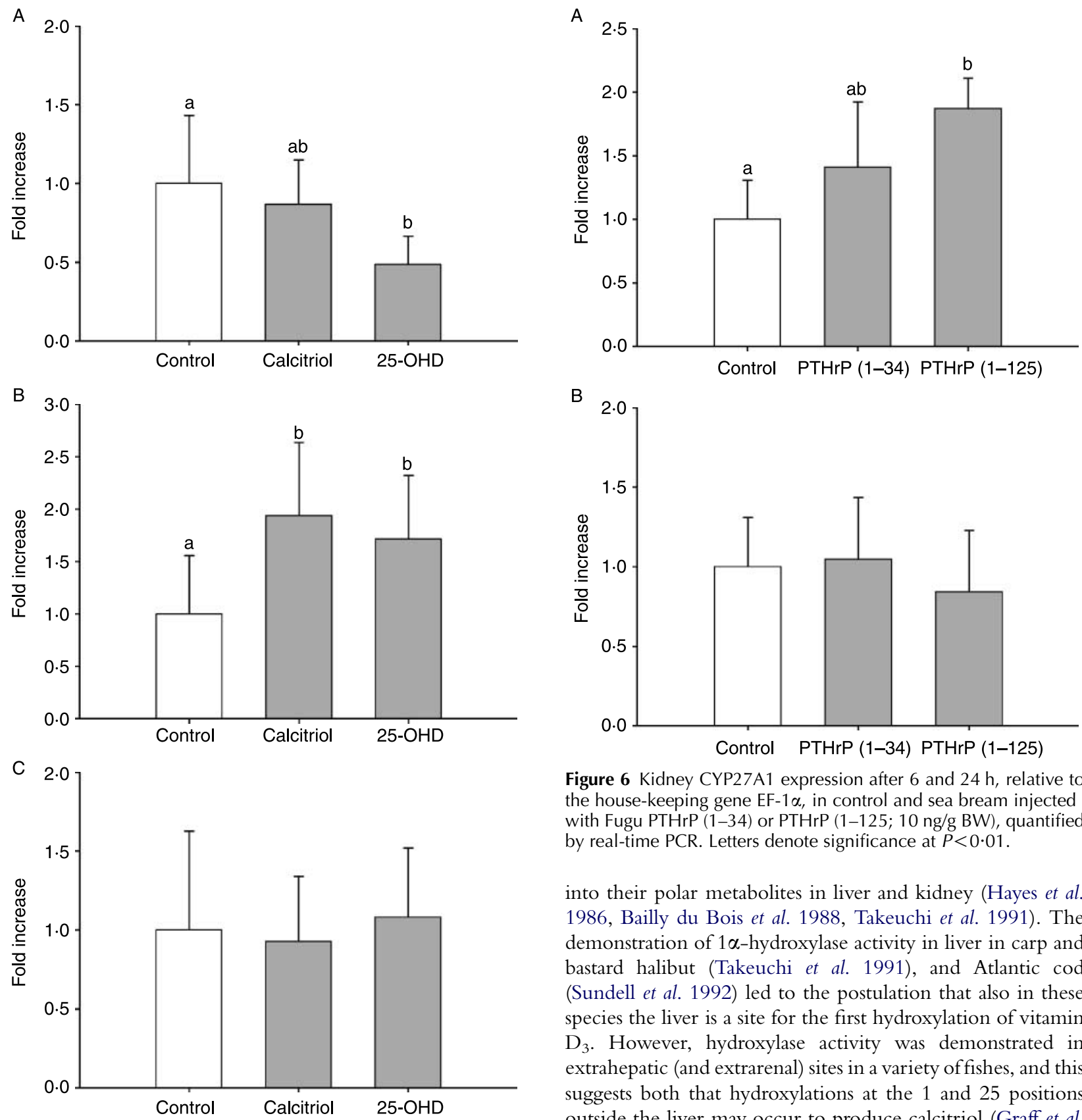

Figure 6 Kidney CYP27A1 expression after 6 and 24 h, relative to the house-keeping gene EF- $1 \alpha$, in control and sea bream injected with Fugu PTHrP (1-34) or PTHrP (1-125; 10 ng/g BW), quantified by real-time PCR. Letters denote significance at $P<0 \cdot 01$.

into their polar metabolites in liver and kidney (Hayes et al. 1986, Bailly du Bois et al. 1988, Takeuchi et al. 1991). The demonstration of $1 \alpha$-hydroxylase activity in liver in carp and bastard halibut (Takeuchi et al. 1991), and Atlantic cod (Sundell et al. 1992) led to the postulation that also in these species the liver is a site for the first hydroxylation of vitamin $\mathrm{D}_{3}$. However, hydroxylase activity was demonstrated in extrahepatic (and extrarenal) sites in a variety of fishes, and this suggests both that hydroxylations at the 1 and 25 positions outside the liver may occur to produce calcitriol (Graff et al. 1999). Considering the situation in mammals with a possible involvement of CYP27B1 in calcitriol metabolism, a further search for analogous hydroxylation pathways in fish seems warranted.

In the mammalian kidney, CYP27B1 hydroxylates 25-OHD to produce circulating calcitriol; remarkably, renal CYP27A1 may also catalyze $1 \alpha$-hydroxylation (Postlind et al. 2000, Araya et al. 2003), and this implies that CYP27A1 may convert vitamin $\mathrm{D}_{3}$ into calcitriol.

In sea bream, just as in higher vertebrates, the expression of CYP27A1 is seen in a variety of tissues; remarkably, studies showed hydroxylation of vitamin $\mathrm{D}_{3}$ and 25-OHD 
the highest expression is observed in kidney and, from our quantitative mRNA analysis, little or none in liver. Also, and in contrast to reports on mammals, we could not alter liver CYP27A1 expression by 'classical' hormonal treatments, while renal CYP27A1 expression markedly responded to both calcitriol and 25-hydroxycholecalciferol. We conclude that the fish kidney may be the prime and possibly unique site for calcitriol formation, a situation clearly different from the two-step process in liver and kidney observed in mammals.

Our findings contrast with those of Takeuchi et al. (1991), who demonstrated that in carp and bastard halibut 25-hydroxylase activity is essentially confined to a hepatic microsomal fraction, and $1 \alpha$-hydroxylase activity to renal and hepatic mitochondrial fractions (Takeuchi et al. 1991), which favors either a liver-renal or liver-liver pathway for dihydroxylation of vitamin $\mathrm{D}_{3}$. Very low-expression levels of the mitochondrial CYP27A1 were found in sea bream liver and no effects could be established of vitamin D metabolite treatments and, therefore, we doubt whether in sea bream the liver plays a role in calcitriol formation; this would imply a renal-renal pathway for dihydroxylation in this species. Clearly, in fish, calcitriol production pathways may differ.

\section{Responses to hormone treatments}

The 25-OHD treatment predictably elevated plasma level of this metabolite reaching its maximum 6 days post-injection. Under this 25-OHD regimen, CYP27A1 expression showed an initial downregulation at day 3 followed by a transient upregulation at day 6. A plethora of receptors and pathways may be involved in regulation following 25-OHD treatment; to establish the factor responsible for the upregulation seen here requires more research (Langmann et al. 2005, Tang 2007, personal communication). We speculate that injection of 25-OHD elevated calcitriol levels (unfortunately, we were not able to assess plasma calcitriol levels) and by doing so enhanced expression of CYP27A1 (for calcitriol effects, see below).

Calcitriol injection was without effect after 3 days; however, after 6 days a twofold upregulation could be seen as in the 25-OHD-treated animals. In mammals, downregulation by calcitriol on CYP27A1 has been reported (Theodoropoulos et al. 2003), but the pattern we show here parallels data on Atlantic salmon: it was shown that calcitriol injections result initially in a drop of plasma calcitriol 3 days after the injection and then return to normal levels (on 5 and 7 days of post-injection); these findings suggest a clearance of the exogenous calcitriol and a suppression of the endogenous production of calcitriol in the first days of post-injection by downregulation of its hydroxylase, followed by an upregulation restoring basal levels. Such effects were also observed in salmon treated with calcitriol (Flik et al. unpublished).

The involvement of CYP27A1 in sea bream vitamin D metabolism is further supported by the upregulation of the gene when fish are subjected to PTHrP. Interactions of the vitamin D system and PTHrP in fishes are essentially unknown, with the exception of one study in which the calcium regulation in vitamin D-deficient sea bream was studied and a relationship was found between PTHrP and calcitriol (Abbink et al. 2007). In humans, when exogenous PTHrP or PTH is administered, calcitriol levels tend to rise (Fraher et al. 1992, Everhart-Caye et al. 1996). Moreover, in a study looking at the vitamin D metabolism in a rat model for humoral hypercalcemia of malignancy, it was established that PTHrP enhanced $1 \alpha$-hydroxylase expression in bisphosphonate-treated rats (Michigami et al. 2001). PTHrP is a well-established hypercalcemic hormone in sea bream and thus we tentatively conclude that PTHrP may well be involved in CYP27A1 regulation, may be to evoke hypercalcemia via CYP27A1-dependent calcitriol production to control calcium uptake. Interestingly, a similar interrelationship between PTHrP and hypercalcemic actions of estrogen was established in this fish (Guerreiro 2002).

\section{Acknowledgements}

The authors declare that there is no conflict of interest that would prejudice the impartiality of this scientific work. Wout Abbink is thanked for his support and advice during these studies. Ms Joana Amaral from Viveiro Villanova, Portugal, is acknowledged for the production of top-quality fish. The crew of the laboratory in Faro is thanked for their great hospitality. This work was carried out with financial support from the Commission of the European Union, Quality of Life and Management of Living Resources specific RTD program (ZQ5RS-2001-02904).

\section{References}

Abbink W \& Flik G 2007 Parathyroid hormone-related protein in teleost fish. General and Comparative Endocrinology 152 243-251.

Abbink W, Hang XM, Guerreiro PM, Spanings FA, Ross HA, Canario AV \& Flik G 2007 Parathyroid hormone-related protein and calcium regulation in vitamin D-deficient sea bream (Sparus auratus). Journal of Endocrinology 193 473-480.

Aiba I, Yamasaki T, Shinki T, Izumi S, Yamamoto K, Yamada S, Terato H, Ide H \& Ohyama Y 2006 Characterization of rat and human CYP2J enzymes as Vitamin D 25-hydroxylases. Steroids 71 849-856.

Altschul SF, Gish W, Miller W, Myers EW \& Lipman DJ 1990 Basic local alignment search tool. Journal of Molecular Biology 215 403-410.

Andersson S, Davis DL, Dahlback H, Jornvall H \& Russell DW 1989 Cloning, structure, and expression of the mitochondrial cytochrome P-450 sterol 26-hydroxylase, a bile acid biosynthetic enzyme. Journal of Biological Chemistry $2648222-8229$.

Anjos L, Rotllant J, Guerreiro PM, Hang X, Canario AV, Balment R \& Power DM 2005 Production and characterisation of gilthead sea bream (Sparus auratus) recombinant parathyroid hormone related protein. General and Comparative Endocrinology 143 57-65.

Araya Z, Hosseinpour F, Bodin K \& Wikvall K 2003 Metabolism of 25-hydroxyvitamin $\mathrm{D}_{3}$ by microsomal and mitochondrial vitamin $\mathrm{D}_{3}$ 25-hydroxylases (CYP2D25 and CYP27A1): a novel reaction by CYP27A1. Biochimica et Biophysica Acta 1632 40-47.

Babiker A, Andersson O, Lund E, Xiu RJ, Deeb S, Reshef A, Leitersdorf E, Diczfalusy U \& Bjorkhem I 1997 Elimination of cholesterol in 
macrophages and endothelial cells by the sterol 27-hydroxylase mechanism. Comparison with high density lipoprotein-mediated reverse cholesterol transport. Journal of Biological Chemistry 272 26253-26261.

Bailly du Bois M, Milet C, Garabedian M, Guillozo H, Martelly E, Lopez E \& Balsan S 1988 Calcium-dependent metabolism of 25-hydroxycholecalciferol in silver eel tissues. General and Comparative Endocrinology 71 1-9.

Bevelander GS, Hang X, Abbink W, Spanings T, Canario AV \& Flik G 2006 $\mathrm{PTHrP}$ potentiating estradiol-induced vitellogenesis in sea bream (Sparus auratus L). General and Comparative Endocrinology 149 159-165.

Bhattacharyya MH \& DeLuca HF 1974 The regulation of calciferol25-hydroxylase in the chick. Biochemical and Biophysical Research Communications $\mathbf{5 9}$ 734-741.

Bjorkhem I, Holmberg I, Oftebro H \& Pedersen JI 1980 Properties of a reconstituted vitamin $\mathrm{D}_{3} 25$-hydroxylase from rat liver mitochondria. Journal of Biological Chemistry 255 5244-5249.

Cali JJ \& Russell DW 1991 Characterization of human sterol 27-hydroxylase. A mitochondrial cytochrome P-450 that catalyzes multiple oxidation reaction in bile acid biosynthesis. Journal of Biological Chemistry 266 7774-7778.

Danks JA, Ho PM, Notini AJ, Katsis F, Hoffmann P, Kemp BE, Martin TJ \& Zajac JD 2003 Identification of a parathyroid hormone in the fish Fugu rubripes. Journal of Bone and Mineral Research 18 1326-1331.

Everhart-Caye M, Inzucchi SE, Guinness-Henry J, Mitnick MA \& Stewart AF 1996 Parathyroid hormone (PTH)-related protein(1-36) is equipotent to PTH(1-34) in humans. Journal of Clinical Endocrinology and Metabolism 81 199-208.

Fraher LJ, Hodsman AB, Jonas K, Saunders D, Rose CI, Henderson JE, Hendy GN \& Goltzman D 1992 A comparison of the in vivo biochemical responses to exogenous parathyroid hormone-(1-34) [PTH-(1-34)] and PTH-related peptide-(1-34) in man. Journal of Clinical Endocrinology and Metabolism 75 417-423.

Gensure RC, Ponugoti B, Gunes Y, Papasani MR, Lanske B, Bastepe M, Rubin DA \& Juppner H 2004 Identification and characterization of two parathyroid hormone-like molecules in zebrafish. Endocrinology 145 1634-1639.

Graff IE, Lie O \& Aksnes L 1999 In vitro hydroxylation of Vitamin $\mathrm{D}_{3}$ and 25-hydroxyvitamin $\mathrm{D}_{3}$ in tissues of Atlantic salmon Salmo salar, Atlantic mackerel Scomber scombrus, Atlantic halibut Hippoglossus hippoglossus and Atlantic cod Gadus morhua. Aquaculture Nutrition 5 23-32.

Guerreiro PM 2002 Calcium balance in the larval and juvenile gilthead sea bream, Sparus aurata. PhD Thesis.

Guerreiro PM, Renfro JL, Power DM \& Canario AV 2007 The parathyroid hormone family of peptides: structure, tissue distribution, regulation, and potential functional roles in calcium and phosphate balance in fish. American Journal of Physiology, Regulatory, Integrative and Comparative Physiology 292 R679-R696.

Hang XM, Power D, Flik G \& Balment RJ 2005 Measurement of PTHrP, PTHR1, and CaSR expression levels in tissues of sea bream (Sparus aurata) using quantitative PCR. Annals of the New York Academy of Sciences 1040 340-344.

Hayes ME, Guilland-Cumming DF, Russell RG \& Henderson IW 1986 Metabolism of 25-hydroxycholecalciferol in a teleost fish, the rainbow trout (Salmo gairdneri). General and Comparative Endocrinology 64 143-150.

Henry H \& Norman AW 1975 Presence of renal 25-hydroxyvitamin-D-1hydroxylase in species of all vertebrate classes. Comparative Biochemistry and Physiology, Part B 50 431-434.

Ibarra C, Estrada M, Carrasco L, Chiong M, Liberona JL, Cardenas C, Diaz-Araya G, Jaimovich E \& Lavandero S 2004 Insulin-like growth factor-1 induces an inositol 1,4,5-trisphosphate-dependent increase in nuclear and cytosolic calcium in cultured rat cardiac myocytes. Journal of Biological Chemistry 279 7554-7565.
Jones G, Strugnell SA \& DeLuca HF 1998 Current understanding of the molecular actions of vitamin D. Physiological Reviews 78 1193-1231.

Kumar S, Tamura K \& Nei M 2004 MEGA3: integrated software for molecular evolutionary genetics analysis and sequence alignment. Briefings in Bioinformatics 5 150-163.

Langmann J, Liebisch G, Moehle C, Schifferer R, Dayoub R, Heiduczek S, Grandl M, Dada A \& Schnutz G 2005 Gene expression profiling identifies retinoids as potent inducers of macrophage lipid efflux. Biochimica et Biophysica Acta 1740 155-161.

Larsson D, Nemere I \& Sundell K 2001 Putative basal lateral membrane receptors for 24,25-dihydroxyvitamin $\mathrm{D}(3)$ in carp and Atlantic cod enterocytes: characterization of binding and effects on intracellular calcium regulation. Journal of Cellular Biochemistry 83 171-186.

Larsson D, Nemere I, Aksnes L \& Sundell K 2003 Environmental salinity regulates receptor expression, cellular effects, and circulating levels of two antagonizing hormones, 1,25-dihydroxyvitamin $\mathrm{D}_{3}$ and 24,25-dihydroxy vitamin $\mathrm{D}_{3}$, in rainbow trout. Endocrinology 144 559-566.

Michigami T, Yamato H, Suzuki H, Nagai-Itagaki Y, Sato K \& Ozono K 2001 Conflicting actions of parathyroid hormone-related protein and serum calcium as regulators of 25-hydroxyvitamin D(3)-1 alpha-hydroxylase expression in a nude rat model of humoral hypercalcemia of malignancy. Journal of Endocrinology 171 249-257.

Pfaffl MW, Horgan GW \& Dempfle L 2002 Relative expression software tool (REST) for group-wise comparison and statistical analysis of relative expression levels in real-time PCR. Nucleic Acids Research 30 e36.

Pikuleva IA, Cao C \& Waterman MR 1999 An additional electrostatic interaction between adrenodoxin and P450c27 (CYP27A1) results in tighter binding than between adrenodoxin and p450scc (CYP11A1). Journal of Biological Chemistry 274 2045-2052.

Postlind H, Hosseinpour F, Norlin M \& Wikvall K 2000 27-Oxygenation of C27-sterols and 25-hydroxylation of vitamin $\mathrm{D}_{3}$ in kidney: cloning, structure and expression of pig kidney CYP27A. Biochemical Journal 347 349-356.

Reiss AB, Martin KO, Rojer DE, Iyer S, Grossi EA, Galloway AC \& Javitt NB 1997 Sterol 27-hydroxylase: expression in human arterial endothelium. Journal of Lipid Research 38 1254-1260.

Rotllant J, Guerreiro PM, Redruello B, Fernandes H, Apolonia L, Anjos L, Canario AV \& Power DM 2006 Ligand binding and signalling pathways of PTH receptors in sea bream (Sparus auratus) enterocytes. Cell and Tissue Research 323 333-341.

Sundell K, Bishop JE, Bjornsson BT \& Porman AW 1992 1,25-Dihydroxy vitamin D3 in the Atlantic cod: plasma levels, a plasma binding component and organ distribution of a high affinity receptor. Endocrinology $\mathbf{1 3 1}$ 2279-2286.

Takeuchi A, Okano T \& Kobayashi T 1991 The existence of 25-hydroxyvitamin $\mathrm{D}_{3}-1$ alpha-hydroxylase in the liver of carp and bastard halibut. Life Sciences 48 275-282.

Theodoropoulos C, Demers C, Petit JL \& Gascon-Barre M 2003 High sensitivity of rat hepatic vitamin $\mathrm{D}_{3}-25$ hydroxylase CYP27A to $1,25-$ dihydroxyvitamin $\mathrm{D}_{3}$ administration. American Journal of Physiology, Endocrinology and Metabolism 284 E138-E147.

\section{Received in final form 12 December 2007 Accepted 17 December 2007} Made available online as an Accepted Preprint 17 December 2007 